\title{
An Outdoor Orientation Program in its Infancy, Student Perception Influencing Best Practice
}

\author{
Luke Pickard and Julie Brunton
}

Outdoor orientation programs (OOP) use adventure experience to aid transition to university. Transition processes are achieved by helping students develop constructive social support systems as well as providing them with feelings of belonging, trust, and connection to a group of peers. These peer relationships provide both critical emotional support and strengthen educational gains (Bell, Gass, Nafziger, \& Starbuck, 2014). Important markers of success at university are academic attainment, retention, and student development (Bell et al., 2014). All of these are important for both the finances and reputation of universities. Programs vary in length, content, and objectives. Further outcome- and evidence-based studies are needed to examine outdoor orientation program elements to better understand how and what elements support student retention (Cortez, 2014). The aim of the research is to investigate student perceptions of the university's first OOP for its sports-based first-year undergraduates. The university created an evaluation questionnaire to receive feedback on the OOP from students in order to have more informed input in future OOPs. The evaluation questionnaire was analyzed using content analysis. The questionnaire also included eight scale-scored questions. The study had 84 first-year undergraduate participants. The evaluation from students will form specific recommendations that will improve provision for its own students and possibly provide recommendations applicable to other academic institutions with limited experience in facilitating an OOP.

\section{Literature Review}

Issues of student retention are of great importance to universities not just in the UK, but also throughout the world. Student retention rates impact universities in a number of ways, such as their economics and reputation. Retention is a key indicator of student satisfaction. Student satisfaction has also been linked to attainment (Douglas, Douglas, \& Barnes, 2006). Therefore, finding solutions that enhance the student experience to increase retention rates is an area of great interest to universities (Douglas, Douglas, McClelland, \& Davies, 2015). There are two widely used measures of retention in the UK for full-time undergraduates. The

Luke Pickard (l.pickard@leedstrinity.ac.uk) is on the Faculty of the School of Social and Health Sciences, University of Leeds in the United Kingdom Julie Brunton is on the Faculty of the School of Biological Sciences, University of Leeds in the United Kingdom 
first is completion rate, which is the number of students who start a degree course and continue until they obtain their qualifications. The second is the continuation rate, which is the number of students who are enrolled in higher education in the year following their first entry to a university (Higher Education Statistics Authority, 2015).

According to Thomas (2012), effective interventions start pre entry, develop peer networks and friendships, place an emphasis on engagement, nurture belonging, and develop confidence. This belief is shared in elements of Tinto's (1993) student integration model. This model states that effective retention programs are committed to the development of social and educational communities, put student welfare above institutional goals, and are committed to the education of the students. The model also suggests ways in which these targets can be achieved. They include the involvement of both staff and students. Programs should be developed over a long term, be developed in collaboration with students, and be continually assessed and altered based on student needs. Quality relationships with roommates may encourage them to stay (Hawken, Duran, \& Kelly, 1991). Students who participate in extracurricular activities, establish close friendships, and maintain student faculty relationships are less likely to leave a university (Martin, 2011). Creating an environment where students have access to support networks appears to be an integral factor influencing student retention (Tinto, 2006).

The theory of student involvement (Astin, 1984) further supports the ideas put forward to create effective retention programs. Astin (1984) found that student persistence is often related to levels of student involvement with the higher education institution (HEI) and is further enhanced through meaningful contact with staff and other students. Through his theory, Astin (1984) also highlights that involvement may naturally vary for different student groups. These groups include students who commute (non-residential), mature students, international students, and students from disadvantaged backgrounds. These groups often encounter more barriers to engaging with the HEI and other students, are less likely to form attachments, and are less embedded in university life (Patiniotis \& Holdsworth, 2005). This, therefore, points to the importance of structuring retention programs to include all student groups and deliver this sense of belonging to the HEI to these groups that are perceived to be less involved, less integrated, and subsequently more likely to leave a HEI.

The research into retention schemes and the factors they seek to influence and develop within students are closely aligned to the mainly North American phenomenon of wilderness orientation programs and outdoor orientation programs. Outdoor orientation programs (OOPs) benefit students in a number of ways, including enhancement of relationships with peers and academic staff; they have also been found to aid personal growth (Vlamis et al., 2011). The benefits of OOPs that aid transition into higher education have also been cited as key components in reducing attrition and increasing adherence to three-year programs of study (Schofield \& Dismore, 2010).

Outdoor orientation programs use adventure experience to aid transition 
to the university. They are usually delivered in small groups of 15 or fewer and involve camping or staying over for at least one night (Bell, Holmes, \& Williams, 2010). Transition processes are achieved by helping students develop constructive social support systems, as well as providing them with feelings of belonging, trust, and connection to a group of peers. These peer relationships provide both critical emotional support and strengthen educational gains (Bell et al., 2014). This connection to peers is of particular interest given the implications of the highlighted retention literature.

Outdoor orientation programs create customs, behaviors, and incidents shared by the participating members to which they can refer and employ as the basis of further interactions (Bell, Holmes, \& Williams, 2010). It has been proposed that "the single most powerful source of influence on the undergraduate student's academic and personal development is the peer group" (Astin, 1993, p. 3). This statement may demonstrate why outdoor orientation programs can be an important tool in enabling a smooth transition to university life. The program provides an environment that fosters friendship formation. These friendships can provide emotional support (Bell, 2007, 2012), further providing them with feelings of belonging, trust, and connection to a group of peers (Bell, 2005a).

The role of staff, instructors, or service providers could be one of the key factors in the success of outdoor orientation programs (Khafaji, 2012). An effective instructor often facilitates the interaction with the physical environment. Instructors teach participants how to perform the skills that are essential in the physical environment (McKenzie, 2003). Finally, within the social environment instructors often work to facilitate the reorganization of thinking at the core of affective growth in the participants (Khafaji, 2012). This important role in the program requires the service providers to have certain key qualities. On the basis of their model, Walsh and Golins (1976) state that instructors must show empathy, be genuine, and be willing to confront participants when they are not displaying the required behavior. This type of retention intervention is also a good way for academic staff to be introduced and interact with students on a more social level, which can break down barriers and improve interaction (Thomas, 2012).

The role of specific activities is another key factor in the success of outdoor orientation programs (Khafaji, 2012). Activities can range in type and purpose. Some pose challenging problem-solving tasks participants must complete, while others are more experience based. These tasks range from physical activities, such as rock climbing and hiking, to activities such as trust exercises (McKenzie, 2000). Khafaji (2012) highlights a number of criteria to which activities should adhere:

1. Challenges should be concrete and manageable, as well as time and space limited.

2. The participants must have the ability to solve the task in order for learning to occur.

3. The activities and tasks must be structured so that there are natural consequences for the activities and tasks.

4. The challenges should be difficult enough that the participants have to use their full range of personal cognitive, emotional, and psychomotor 
resources in order to complete the tasks. Participants are more likely to retain the lessons learned from successfully completing the activity or task if the challenge is extremely difficult (Priest \& Gass, 2005).

5. The difficulty level should be set so that the participants question whether they will be able to accomplish the task or activity; however, the difficulty should not so exceed their abilities that they are unable to believe they can succeed.

The location of the outdoor orientation is also an important issue. Thompson Coon et al. (2011) investigated whether outdoor activity was more beneficial than activity delivered indoors in a gym style setting. The research found that green activity participants adhered to schemes for longer and reported better wellbeing. In addition, the green schemes also appealed to some people who reported not enjoying "traditional gym exercise." Participants also expressed feelings of escapism from city life and a connection with the natural environment. These are important aspects of the outdoor orientation experience. Further research could investigate what specific types of environment are most beneficial and complementary to the outdoor orientation programs.

Programs vary in length, content, and objectives. Sibthorp, Paisley, and Gookin (2007) stated that adventure programs continue to rely on descriptive or anecdotal evidence rather than investigate what elements lead to specific participant development and program outcomes. Further outcome- and evidence-based studies are needed to examine outdoor orientation program elements to better understand how and what elements support student development (Cortez, 2014). These critiques provide a starting point for the current research project. There is an opportunity to investigate the key aspects of outdoor orientation programs to determine the most effective "blueprint." The current research could provide specific recommendations on program content, which could benefit universities' retention rates and student satisfaction countrywide if similar outdoor orientation programs are adopted.

The current study is focussed on a UK university that first introduced an OOP for its sports-based first-year undergraduates. The OOP was chosen as a strategy to improve student satisfaction and retention based on the success of similar schemes reported in the literature. The OOP took place in the first teaching week of the students' first term. The OOP was a 3-night residential program that incorporated daytime adventure activities followed by short academic sessions in the evening. The specific logistics, including location, accommodation, activities, and schedule, were organized through a third-party outdoor adventure company that has over two decades of experience. This experience was important, yet it restricted the input of the host university. The university created an evaluation questionnaire to receive feedback on the OOP from students in order to have more informed input in future OOPs. The evaluation from students will form specific recommendations that will improve provisions for its own students and possibly provide recommendations applicable to other academic institutions with limited experience in facilitating an OOP. 


\section{Methodology}

The current study involves an open-ended evaluative questionnaire; the level of detail and space within the questionnaire has been limited. Given the parameters of the questionnaire, the research methodology most suited to the analysis of such data is content analysis (Berelson, 1952; Krippendorff, 1980). This methodology allows a range of responses to be incorporated into the analysis not restricted by a "tick box" questionnaire.

Content analysis is a flexible method for analysing textual data (Hsieh \& Shannon, 2005). It can be used in a range of analytical approaches based on the nature of the research question and the interests of the researcher (Graneheim \& Lund, 2003). This variability and flexibility has been the subject of debate regarding the lack of a firm definition and procedure. This has potentially limited the application of the method, yet this flexibility allows the method to be utilized based specifically on the individual study needs (Hsieh \& Shannon, 2005). Content analysis used in this study will take its simplest form as a quantitative research method, with text data coded into explicit categories and then described using statistics. This approach is sometimes referred to as quantitative analysis of qualitative data (Morgan, 1993). This style of content analysis ensures all units of analysis receive equal treatment through an objective process that presents trends, patterns, and differences. Content analysis generally follows six steps (Krippendorff, 1989):

1. Design: analysts define their context and what they wish to know.

2. Unitizing: define and identify units of analysis in the volume of identifiable data.

3. Sampling: ensure the sample is representative of the phenomena under investigation.

4. Coding: describe and classify the meaning units in terms of categories of the analytical constructs chosen.

5. Drawing inferences: apply the stable knowledge of the coded data to the phenomena under investigation.

6. Validation: content analysis should not be undertaken without at least the possibility of bringing validating evidence to bear on the findings.

The literature surrounding content analysis provides a number of concepts of reduction used to shorten the text. The method used within the present study is that of condensation (Coffey \& Atkinson, 1996). The principle of this method is to shorten the text while preserving the core meaning. This is particularly applicable to this study where the questions utilized ask for directive summative answers. The present study intends to record obvious meaning units referred to as manifest content, which is the literal subject matter of the question (Kondracki et al., 2002). This is due to the directness of the evaluative questions asked to the participants; the questions provided little scope for conveying latent content or underlying unexpressed meaning. 


\section{Trustworthiness}

Rigor is the way in which we can establish trust and confidence in qualitative research findings. The way in which this rigor is achieved is a matter of much debate; for example, Lincoln and Guba (1985) propose four criteria that can help establish trustworthiness of a qualitative study. These criteria correspond to positivist investigation. However, the appropriateness of applying quantitative style criteria to qualitative research is, again, a subject of debate. Rigor in the current study will be achieved through credibility and transferability. Credibility deals with the focus of the research and refers to confidence in how well data and processes of analysis address the intended focus (Polit \& Hungler, 1999). The participants were selected for being information rich on the subject under investigation. The approach to gathering data was chosen to minimize demand characteristics resulting from people in a position of power (lecturers or tutors) administering the evaluation questionnaire. The method for data collection was a simple evaluation questionnaire that directly asked questions about the OOP experience; participants could answer in their own words, which gave larger scope for opinion and selfexpression. The participant sample generated enough data required for patterns and trends to emerge, all of which contribute to establishing credibility.

To facilitate transferability, clear description of research subject and participants was given. The data collection and process of analysis procedures were provided, allowing for the study to be replicated. A clear presentation of the analysis is provided to allow the reader the opportunity to decide upon the accuracy and transferability of the research findings. These elements together also enhance transferability.

The research considered a number of additional techniques used to further establish trustworthiness, including triangulation. Investigator triangulation can be defined as the use of more than two researchers in any of the research stages in the same study. It involves the use of multiple observers, interviewers, or data analysts in the same study for confirmation purposes (Hussain, 2009). This was applied in part through the active engagement of academic peers during the analysis process.

\section{Method}

\section{Participants}

Participants were first-year university students, enrolled in a sports-based degree program. The questionnaire did not contain demographic information to allow total anonymity to encourage honesty in evaluating the OOP. All 110 OOP participants were given the OOP evaluation questionnaire, of which 84 were returned. 
A university-created OOP evaluation questionnaire containing the following five questions:

1. What were your expectations and feelings prior to attending the residential?

2. How do you feel now after attending the residential?

3. What did you enjoy the most about the residential?

4. Tell us at least one thing that could have improved your residential experience.

5. Was the timing of the residential appropriate?

The questionnaire also included a short 8-question section rated on a 4-point scale, including the options NA, strongly agree, agree, disagree, and strongly disagree.

\section{Procedure}

On the final afternoon of a 3-day residential OOP, the first-year university undergraduates were asked to collect an OOP evaluation questionnaire when returning from their final activity. Questionnaires were located near the entrance of the YHA building. When completed, there was a returns box for the questionnaire, again, located in the YHA building entrance.

\section{Analysis and Discussion}

\section{Question 1: What were your expectations and feelings prior to attending the residential?}

Figure 1 demonstrates the overriding feelings and expectations of students prior to attending the OOP. The main expectation was to meet people, course mates and academic staff and make friends (20\%). This is very encouraging as it suggests students were aware and open to the possibility of friendship formation. These peer relations are one of the key factors in aiding student transition to the university (Bell, 2012). Furthermore, staff and student interaction can help aid belonging to a university (Bell et al., 2014) Students were also expecting to be involved in lots of activities (16\%). The idea that students were generally aware of the structure of an OOP is also an interesting point. It ties in with the responses such as excitement, fun, expecting adventure and challenges, and learning new skills. It can also be associated with low expectations and not wanting to go. This may be explained by previous experience of similar events which have been poorly managed, these negative answers were more surprising especially the "didn't want to go" as the OOP was not compulsory. In fact $24 \%$ of expectations and feelings were negative towards the OOP. The largest of which was nervous/worried or anxious, this accounted for $9 \%$ of all responses. This is an underreported aspect of a first-year student experience. Being nervous or anxious when meeting a 


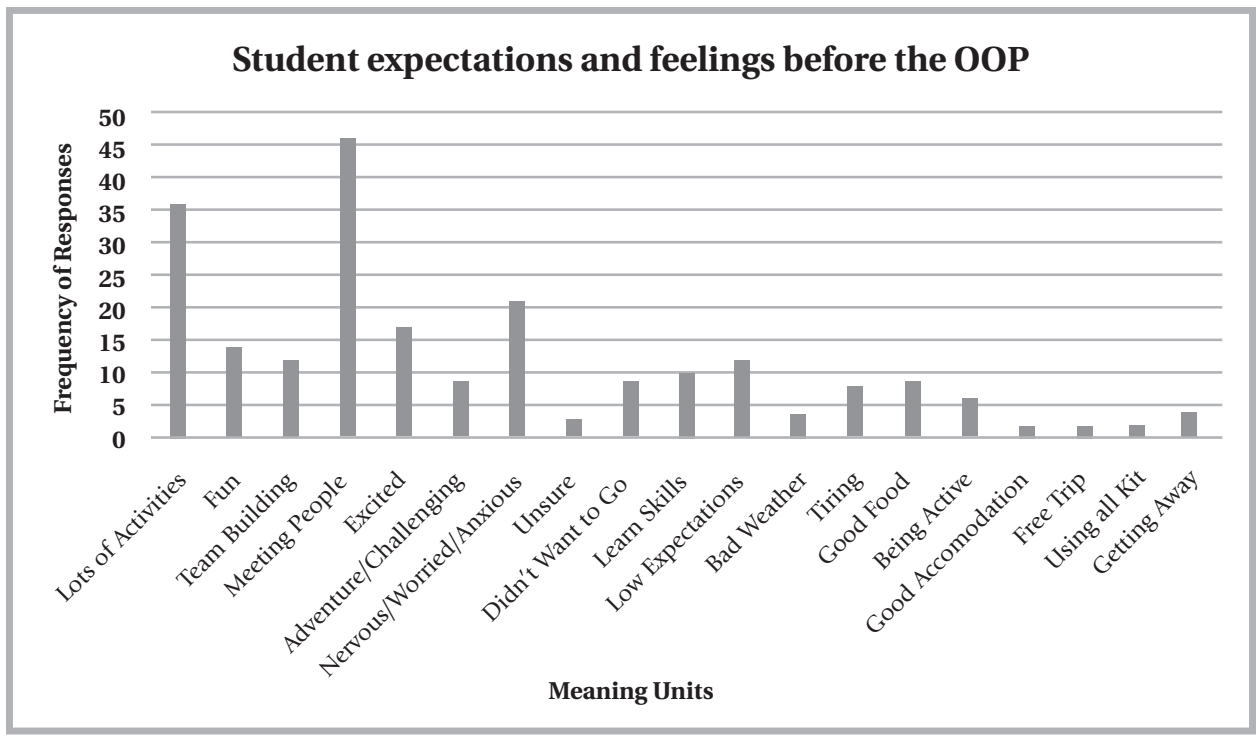

Figure 1.

large group of new people in an unfamiliar setting would affect even the most confident of people and the OOP can help counteract these feelings by providing opportunity to meet people in a friendly atmosphere bonding people through shared experience (Bell, Holmes and Williams, 2010).

\section{Question 2: How do you feel now after attending the residential?}

Figure 2 shows a large range of responses. The student feeling and opinion after attending the OOP was generally split: $56 \%$ of responses were positive, and $44 \%$ of the answers were negative. The most common responses were "made friends" (21\%). This is an important finding given the goals of the OOP. There were 84 respondents, and of these, 49 reported that they had made friends; this type of response justifies the use of OOP to build peer relations and friendships (Bell et al., 2014). This may have helped some students (11 respondents) in increased confidence. Many of the respondents (30 respondents) also stated they enjoyed the OOP or the activities. Of the negative responses, $11 \%$ were tiredness, which is to be expected given the physical and full nature of the OOP. More worrying responses were unsure of the point and wouldn't go back. The response of "not challenging" is also of interest as this is one of the key principles in OOPs. The third highest response was the students felt they needed more or improved activities. The negative feelings expressed can be tackled through better program management. 


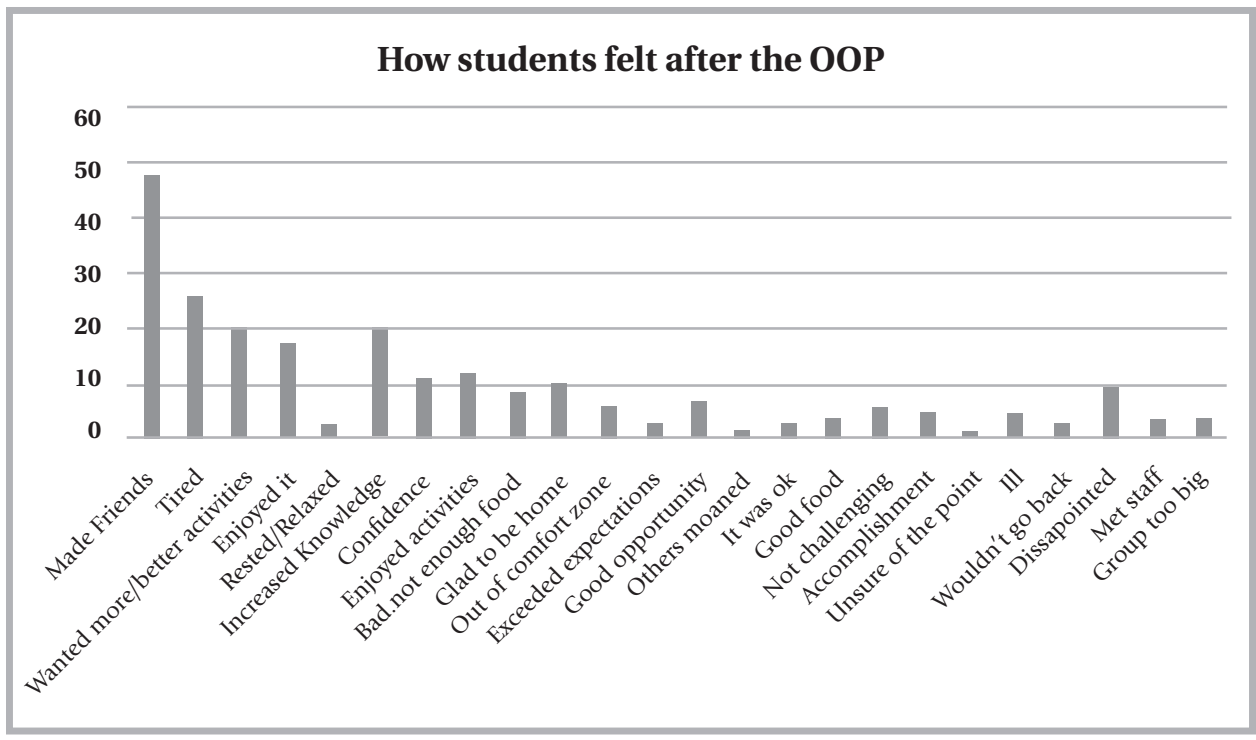

Figure 2. A bar chart to show student feelings following the OOP

Issues like "unsure of the point" can be addressed through clear, brief instruction prior to the start of the OOP. Other issues, such as food and number and type of activities, can also be enhanced prior to the next intake of first-year undergraduate students. The most encouraging aspect of this set of results is the point that many of the students made friends and enjoyed the experience. The amount and nature of the negative responses also demonstrates the method with which the evaluation questionnaire was administered and collected was appropriate for the study by providing anonymity. The expression of negative feelings towards the current OOP will serve to improve the organization and subsequent experience for future students. A large number of meaning units were used for this question; this was a deliberate action to allow the reader to see the range of positives and negatives expressed by the student participants, therefore, providing a fuller picture of their thoughts, feelings, and experiences.

\section{Question 3: What did you enjoy the most about the residential?}

Figure 3 shows the responses concerning the most enjoyable elements of the OOP. Activities (62\%) and making friends (31\%) were the overwhelming majority of responses. Despite the fact in the previous question, a number of students stated they would like more or improved activities, the activities that did take place were the most enjoyable part of the OOP. This can help with future planning of 


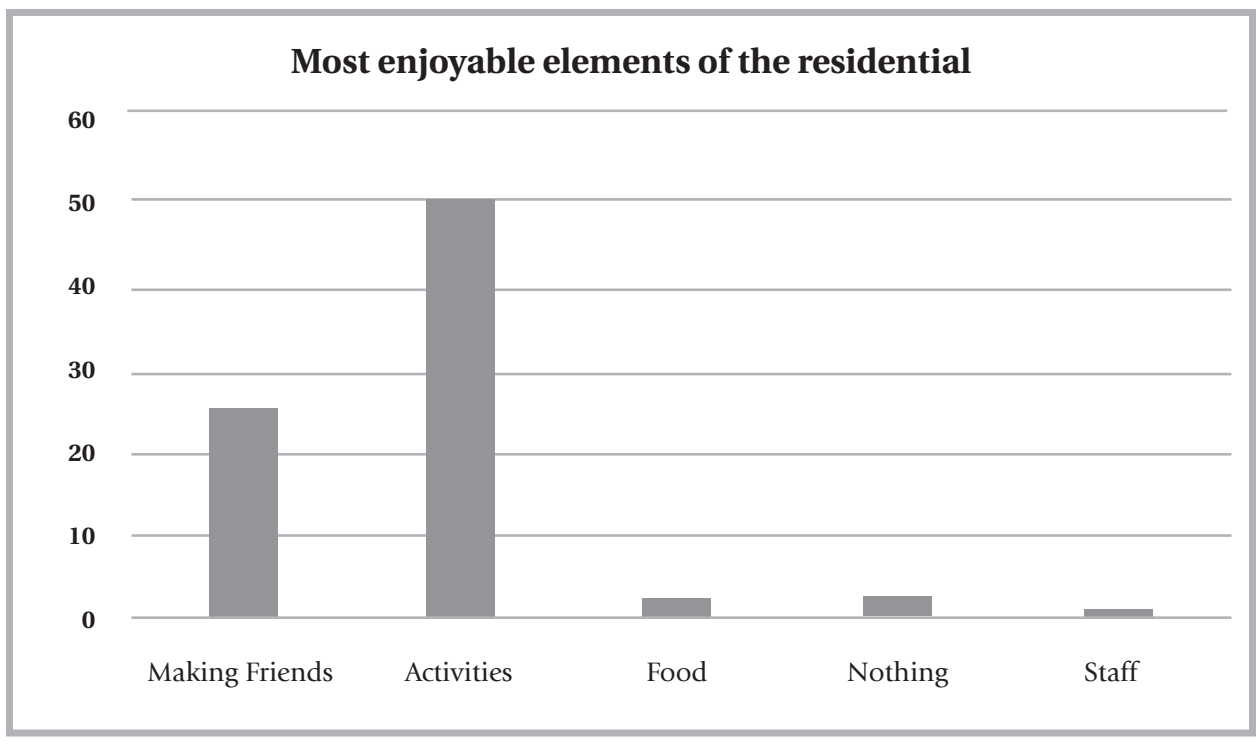

Figure 3. A bar chart to show most enjoyable elements of the OOP

OOPs. The activities undertaken can be retained for future OOPs with additional activities added to improve the schedule. Again, forming friendships with peers was at the forefront of many students' thoughts about the OOP. The responses to this question provide support for the successfulness of the OOP experience for students. It is worth noting that despite the question asking for positives, $4 \%$ of answers were negative. Three students said they enjoyed no elements of the OOP, and this may be a slight cause for concern. By addressing the problems raised in the previous question and improving the activity schedule in future OOPs, all students will enjoy the experience.

\section{Question 4: Tell us at least one thing that could have improved your residential experience.}

Figure 4 shows the responses students gave to things they would do to improve the OOP. There were four main responses to this question, two of which concerned the activities. Students wanted more activities (24\%) and a greater choice of activities (23\%). This echoes the student sentiment expressed in Question 2. These were the two highest responses and, therefore, take on the greatest significance when making adjustments to the OOP schedule for future year groups. The next highest response was better food (19\%) that will be discussed with the operator to ensure mealtime runs more smoothly in future OOPs. Students also revealed 
that the OOP could have been better organized (18\%). This is a disappointing finding, yet it was the university's first OOP, and this lack of experience may have contributed to this feeling. As the university becomes more accustomed to organizing this type of event and student feedback is taken into consideration, the organizational structure can only improve. This should enhance student experience of the OOP. The other score of note was $9 \%$ were unhappy with the accommodation or rooms. The main concern highlighted with the rooms was the large dormitory style of room was not appropriate for this type of event.

\section{Figure 4}

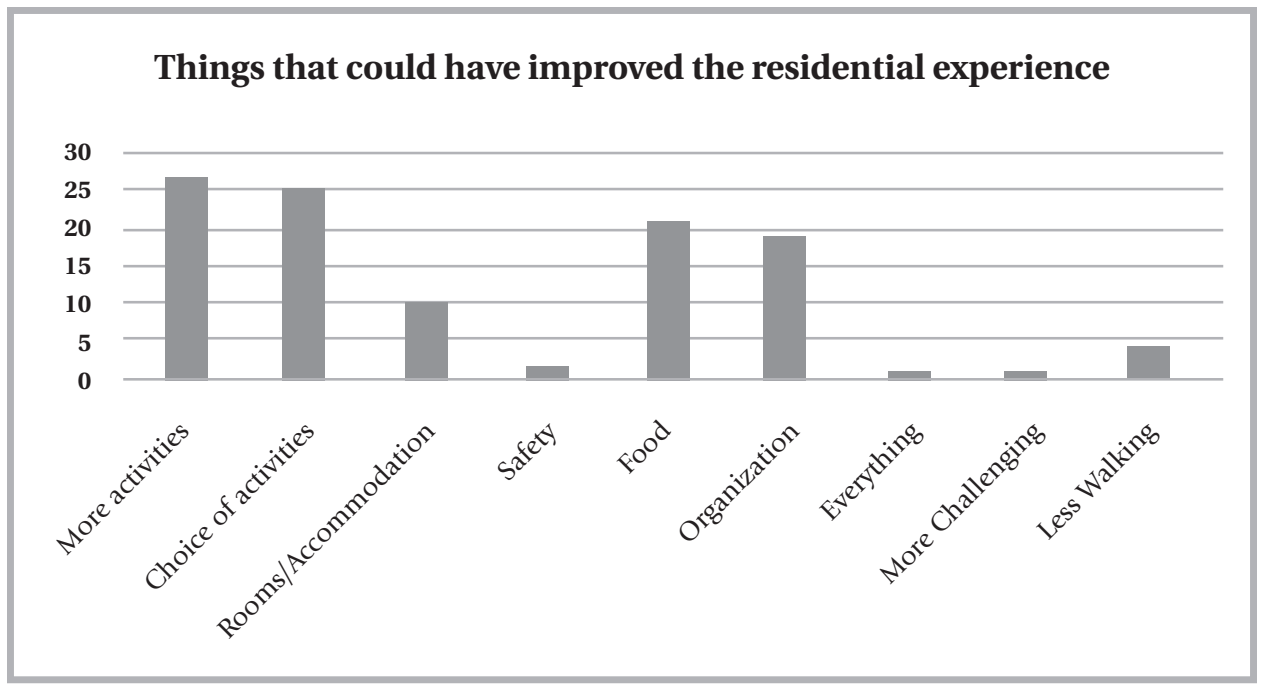

Figure 4. A bar chart to show things to improve the OOP experience

\section{Question 5: Was the timing of the residential appropriate?}

Figure 5 shows the student response to the timing of the OOP. The majority of responses were in favor of the timing (71\%) versus not favoring the timing $(29 \%)$. This provides support for the timing of the OOP, which was in the first teaching week of term. This gave residential students time to move into halls of residence and all students the opportunity to take part in "freshers week" before the OOP began.

The open-ended questions were supplemented by a short scale-based section of the questionnaire. 


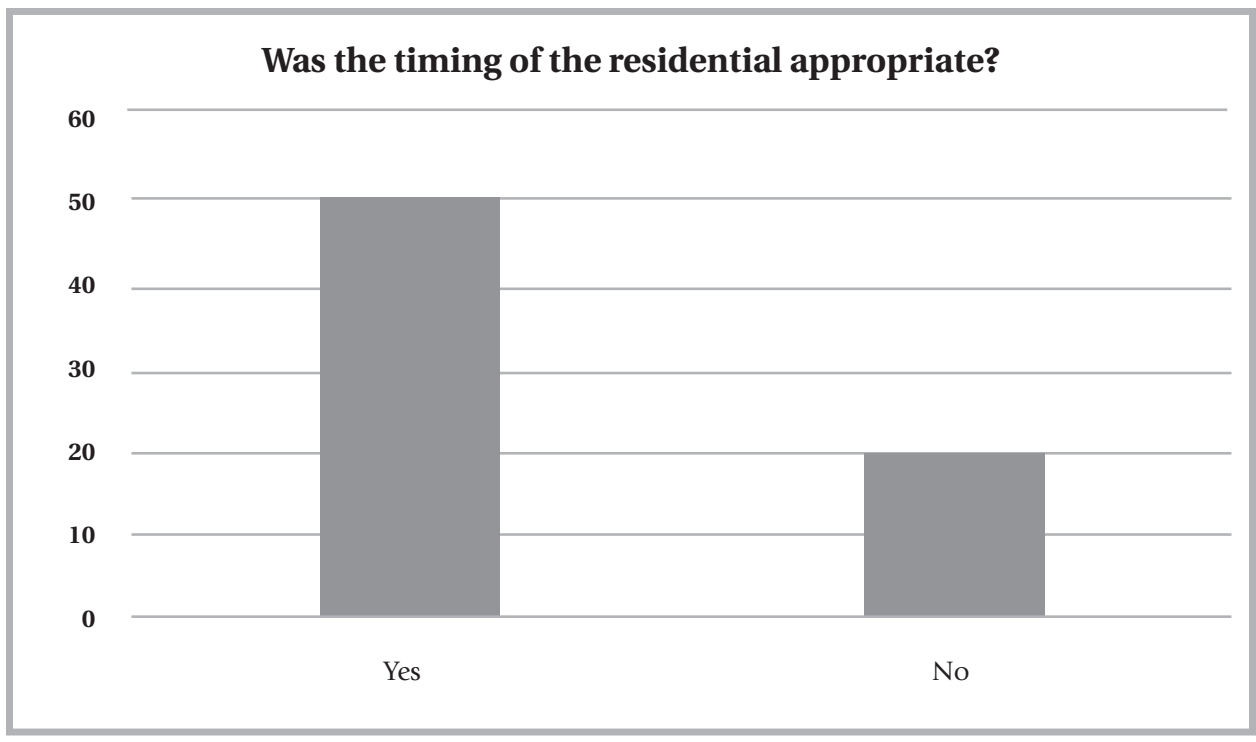

Figure 5. A bar chart to show whether the timing of the OOP was appropriate?

Table 1 shows the descriptive statistics of the scale-score aspect of the evaluation questionnaire. The highest scoring was the instructor knowledge (mean 5.59), closely followed by activity instructions (mean 3.48). This was a point that was included in both the feelings after the OOP question and the most enjoyable elements of the OOP question, although only by a small number of students. This provides some evidence that the paid staff on site were appropriate for the activities, and they enhanced the student experience. This provides justification for using an outdoor adventure company with vast experience. The lowest scoring question was the range of activities (mean 2.52), although this had the largest standard deviation, indicating a larger spread of scores. This is one of the main points of concern raised from the evaluation questionnaire and is an issue that can be addressed for future OOPs. The accommodation scored second lowest (mean 2.97), and student concerns over accommodation will be acknowledged, such as the large dormitory-style rooms. This is, again, something that can be altered for future first-year students. The scale-scored questions provided validation for the content analysis findings, generally yielding similar results, thereby enhancing the trustworthiness of the content analysis findings and reinforcing the student opinion.

Figure 6 shows that the majority of participants agreed that the accommodation was suitable for the OOP despite its relatively low mean score. Figure 7 shows many of the participants believed the range of activities was not adequate. The spread of score bar charts have been included to provide clarity on the scoring patterns of students for the low-mean-scoring scale questions. 


\section{Descriptive statistics of scale-based questions}

\begin{tabular}{|c|c|c|c|c|c|}
\hline & $\mathrm{N}$ & Minimum & Maximum & Mean & Std. Deviation \\
\hline $\begin{array}{l}\text { Venue and location } \\
\text { were suitable for the } \\
\text { activities }\end{array}$ & 74 & 2 & 4 & 3.30 & .516 \\
\hline $\begin{array}{l}\text { Accommodation was } \\
\text { suitable for the OOP }\end{array}$ & 75 & 1 & 4 & 2.97 & .771 \\
\hline $\begin{array}{l}\text { Instructor were } \\
\text { knowledgeable in the } \\
\text { activities }\end{array}$ & 75 & 2 & 4 & 3.59 & .522 \\
\hline $\begin{array}{l}\text { Instructions were } \\
\text { clear for the activities }\end{array}$ & 75 & 0 & 4 & 3.48 & .685 \\
\hline $\begin{array}{l}\text { Good feedback was } \\
\text { provided during } \\
\text { activities }\end{array}$ & 75 & 1 & 4 & 3.03 & .735 \\
\hline $\begin{array}{l}\text { Activities provided } \\
\text { were suitable for the } \\
\text { group }\end{array}$ & 75 & 1 & 4 & 3.19 & .651 \\
\hline $\begin{array}{l}\text { Range of activities } \\
\text { was sufficiently } \\
\text { varied }\end{array}$ & 75 & 1 & 4 & 2.52 & .906 \\
\hline $\begin{array}{l}\text { Location of the } \\
\text { activities was suitable }\end{array}$ & 75 & 2 & 4 & 3.28 & .559 \\
\hline
\end{tabular}

\section{Conclusion}

\section{Implications and Contribution}

The evaluation questionnaire has provided insight into the individual intricate factors at play in OOPs. The main points raised by students were not evident in the reviewed literature, including the number and length of activities and the type of accommodation and food provided. The evaluation questionnaire has provided future OOP design points for consideration for the university. Firstly and most importantly for the students was that more activities need to be included. Organization prior and during the OOP needs improvement; this included meal 
time structure and type of room allocation. The study also found the timing of the OOP was well selected by the university. Overall, students enjoyed the activities, and the OOP, in general, facilitated the development of friendship for many students. The OOP can be considered a success with room for improvement. The logistical things highlighted to improve may appear relatively small, yet tweaking these elements will serve to improve the student experience, which may add to the positives already felt by this year's student intake. Further research is suggested on the impact accommodation type can have on the OOP experience; in the current literature, it can range from tents to hotels, so future research in this area may be useful. Future studies which list and rate activity choices and activity schedules may also provide vital information for not only universities new to OOPs but also in promoting best practice among the more experienced universities and organizers.

\section{Limitations}

The scale-scored element of the evaluation questionnaire could have been scored on a standard 5-point Likert scale (Likert, 1932), including the answer "neither agree or disagree;" this would have given participants greater scoring choice, although the 4-point scale encouraged participants to commit to either a positive or negative response to the questions.

The findings of the evaluation questionnaire are specific to a single developing OOP and a single group of students who experienced the OOP. The study will help improve experience for future students at the host university's OOPs. The findings do not make specific recommendations for all OOPs, but they may provide OOP organizers an insight into what students expect of an OOP and elements that are important to students that may have been overlooked.

\section{Figure 6}

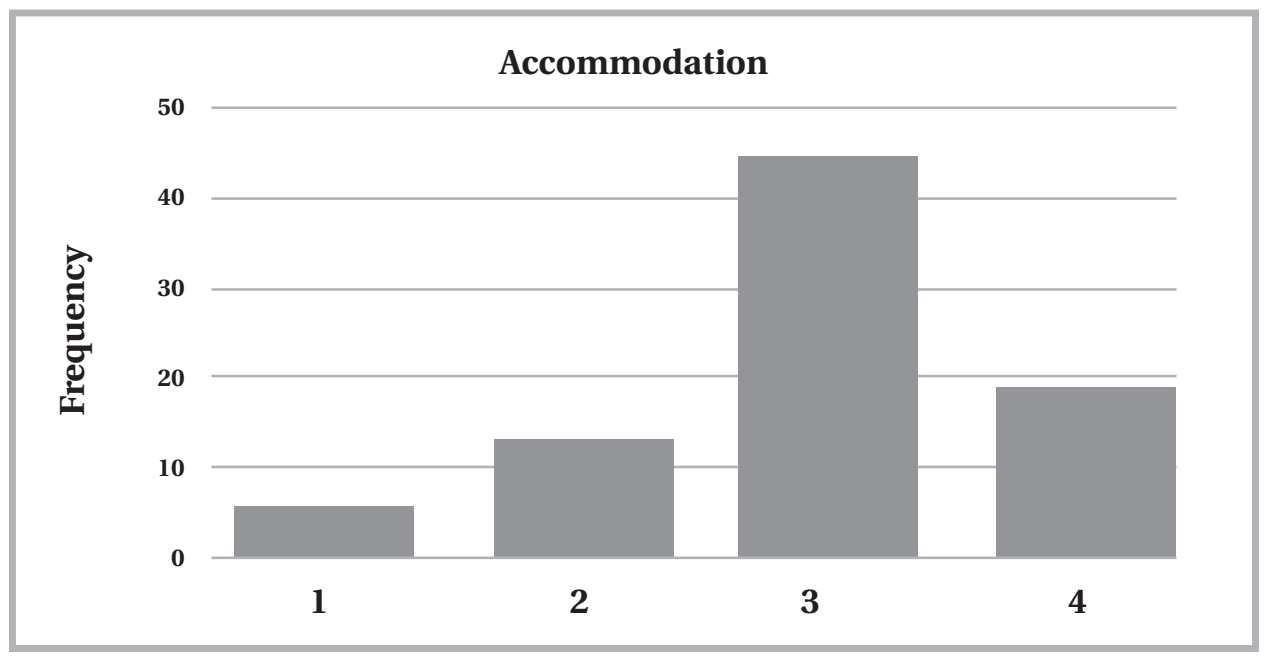

Figure 6. Bar chart displaying spread of scores for accommodation 


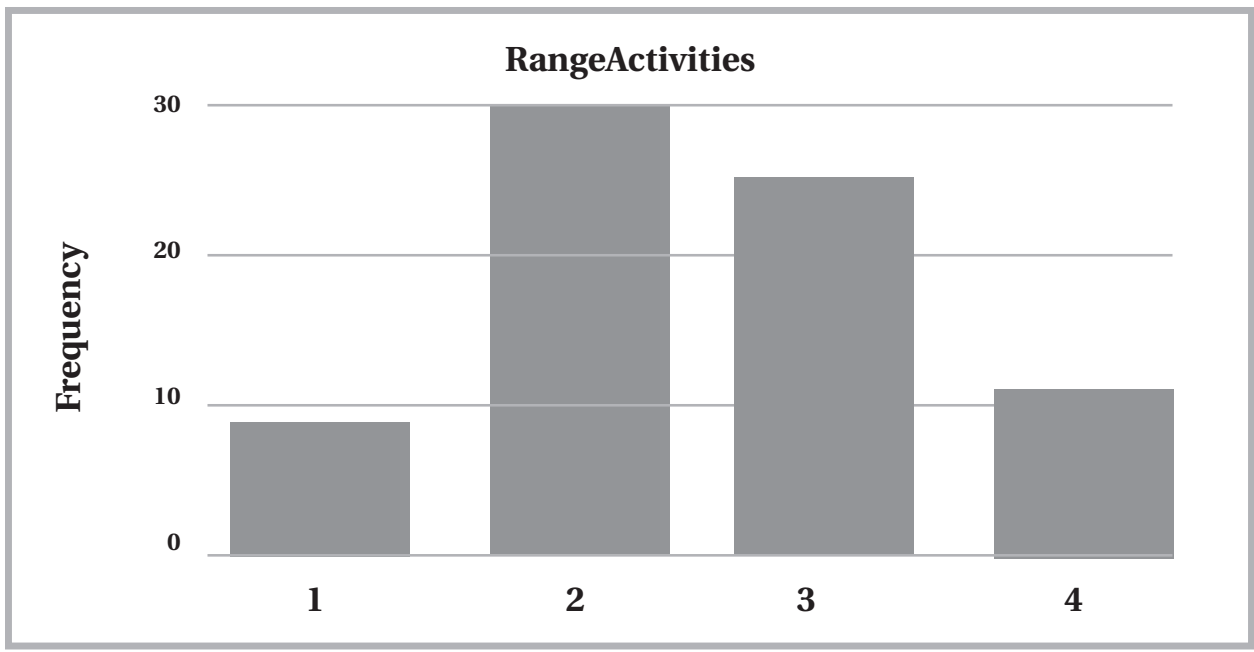

Figure 7. Bar chart displaying spread of scores for range of activities

\section{References}

Astin, A. W. (1984). Student involvement: A developmental theory for higher education. Journal of College Student Personnel, 25(4), 297-308.

Astin, A. W. (1993). What matters in college? Four critical years revisited. San Francisco, CA: Jossey-Bass.

Baker, R. W., \& Siryk, B. (1989). Student adaptation to college questionnaire: Manual. Torrance, CA: Western Psychological Services.

Bean, J. P. (2005). Nine themes of college student retention. In A. Steidman (Ed.), College student retention: Formula for student success (pp. 215-243). Westport, CT: Praeger.

Bell, B. J. (2005a). College students' development of social support and its relationship to preorientation experiences. Unpublished doctoral dissertation, University of New Hampshire, Durham, NH.

Bell, B. J., Holmes, M. R., \& Williams, B. G. (2010). A census of outdoor orientation programs at four-year colleges in the United States. Journal of Experiential Education, 33, 1-18.

Bell, B. J. (2012). Assessing the effectiveness of an adventure-based first year experience class. Journal of College Student Development, 53, 347-355.

Bell, B.J., Gass, M.A., Nafziger, C.S. \& Starbuck, J.D. (2014). The state of knowledge of outdoor orientation programs: Current practices, research, and theory. Journal of Experiential Education, 37(1), 31-45.

Berelson, B. (1952). Content analysis in communication research. Glencoe, IL: Free Press. 
Buote, V. M., Pancer, S. M., Pratt, M. W., Adams, G., Birnie-Lefcovitch, S., Polivy, J., \& Wintre, M. G. (2007). The importance of friends: Friendship and adjustment among 1st-year university students. Journal of Adolescent Research, 22(6), 665689.

Cortez, K. J. (2014). Outcomes assessment of an outdoor orientation program through means-end theory. (Master's thesis). Retrieved from http://scholarworks.gvsu. edu/

Graneheim, U. H., \& Lundman, B. (2004). Qualitative content analysis in nursing research: Concepts, procedures and measures to achieve trustworthiness. Nurse Education Today, 24(2), 105-112.

Hawken, L., Duran, R. L., \& Kelly, L. (1991). The relationship of interpersonal communication variables to academic success and persistence in college. Communication Quarterly, 39, 297-308

Khafaji, S. (2012). It was tough, but it was kind of cool: experience of a university wilderness orientation program through the participants' eyes. Western Carolina University Doctoral dissertation.

Kondracki, N. L., Wellman, N. S., \& Amundson, D. R. (2002). Content analysis: review of methods and their applications in nutrition education. Journal of Nutrition Education and Behavior, 34(4), 224-230.

Krippendorff, K. (1980). Content analysis: An introduction to its methodology. Beverly Hills, CA: Sage Publications.

Krippendorff, K. (1989). On the essential contexts of artifacts or on the proposition that "design is making sense (of things)." Design Issues, 5(2), 9-39

Li, T., \& Cheng, S. T. (2015). Family, friends, and subjective well-being: A comparison between the West and Asia. In M. Demir (Ed.), Friendship and happiness: Across the life-span and cultures (pp. 235-251). Dordrecht, Netherlands: Springer.

Lien, M., \& Goldenberg, M. (2012). Outcomes of a college wilderness orientation program. Journal of Experiential Education, 35(1), 253-271.

Likert, R. (1932). A technique for the measurement of attitudes. Archives of Psychology, 140, 1-55.

Martin, J. M. (2011). What now? What next? A narrative analysis of cross-cultural adaptation and college student retention. (Doctoral dissertation). Retrieved from http://uknowledge.uky.edu

McDonald, J. E., \& Robinson, R. L. (2014). Enhancing first year undergraduate student engagement via the school of biological sciences tutorials module. Bioscience Education, 22(1), 54-69.

Paxton, T., \& McAvoy, L. (2000, May). Social psychological benefits of a wilderness adventure program. In McCool, S.F., Cole, D.N., Borrie, W.T., \& O'Loughlin, J. (comps.). Wilderness science in a time of change conference (Vol. 3; pp. 23-27).

Pittman, L. D., \& Richmond, A. (2008). University belonging, friendship quality, and psychological adjustment during the transition to college. The Journal of Experimental Education, 76(4), 343-362.

Posey, T., Hill, E., Gomez, E., McFall, M., Humenik, S., \& Clifford, D. (2015). Student adjustment to College: Examining the impact of an outdoor 
orientation program. Illuminare: A Student Journal in Recreation, Parks, and Tourism Studies, 13.

Priest, S., \& Gass, M. A. (2005). Effective leadership in adventure programming. Champaign, IL: Human Kinetics.

Ramsing, R., \& Sibthorp, J. (2008). The role of autonomy support in summer camp programs: Preparing youth for productive behaviors. Journal of Park and Recreation Administration, 26(2).

Richardson, A., King, S., Garrett, R., \& Wrench, A. (2012). Thriving or just surviving? Exploring student strategies for a smoother transition to university. The International Journal of the First Year in Higher Education, 3(2), 87-93.

Shim, S. S., \& Ryan, A. M. (2012). What do students want socially when they arrive at college? Implications of social achievement goals for social behaviors and adjustment during the first semester of college. Motivation and Emotion, 36(4), 504-515.

Sibthorp, J., Paisley, K., \& Gookin, J. (2007). Exploring participant development through adventure-based programming: A model from the National Outdoor Leadership School. Leisure Sciences, 29(1), 1-18

Thompson Coon, J., Boddy, K., Stein, K., Whear, R., Barton, J., \& Depledge, M. H. (2011). Does participating in physical activity in outdoor natural environments have a greater effect on physical and mental wellbeing than physical activity indoors? A systematic review. Environmental science \& technology, 45(5), 17611772.

Walsh, V. \& Golins, G. (1976). The exploration of the Outward Bound process. Denver, CO: Colorado Outward Bound School.

Wolfe, B.D. \& Kay, G. (2011). Perceived impact of an outdoor orientation program for first-year university students. Journal of Experiential Education, 34(1), 19-34. 